\title{
Real Time Domestic Power Consumption Monitoring using Wireless Sensor Networks
}

\author{
Venkatsampath Raja Gogineni, Kalyan Matcha, Raghava Rao K
}

Dept. of Electronics and Computers, K L University, India

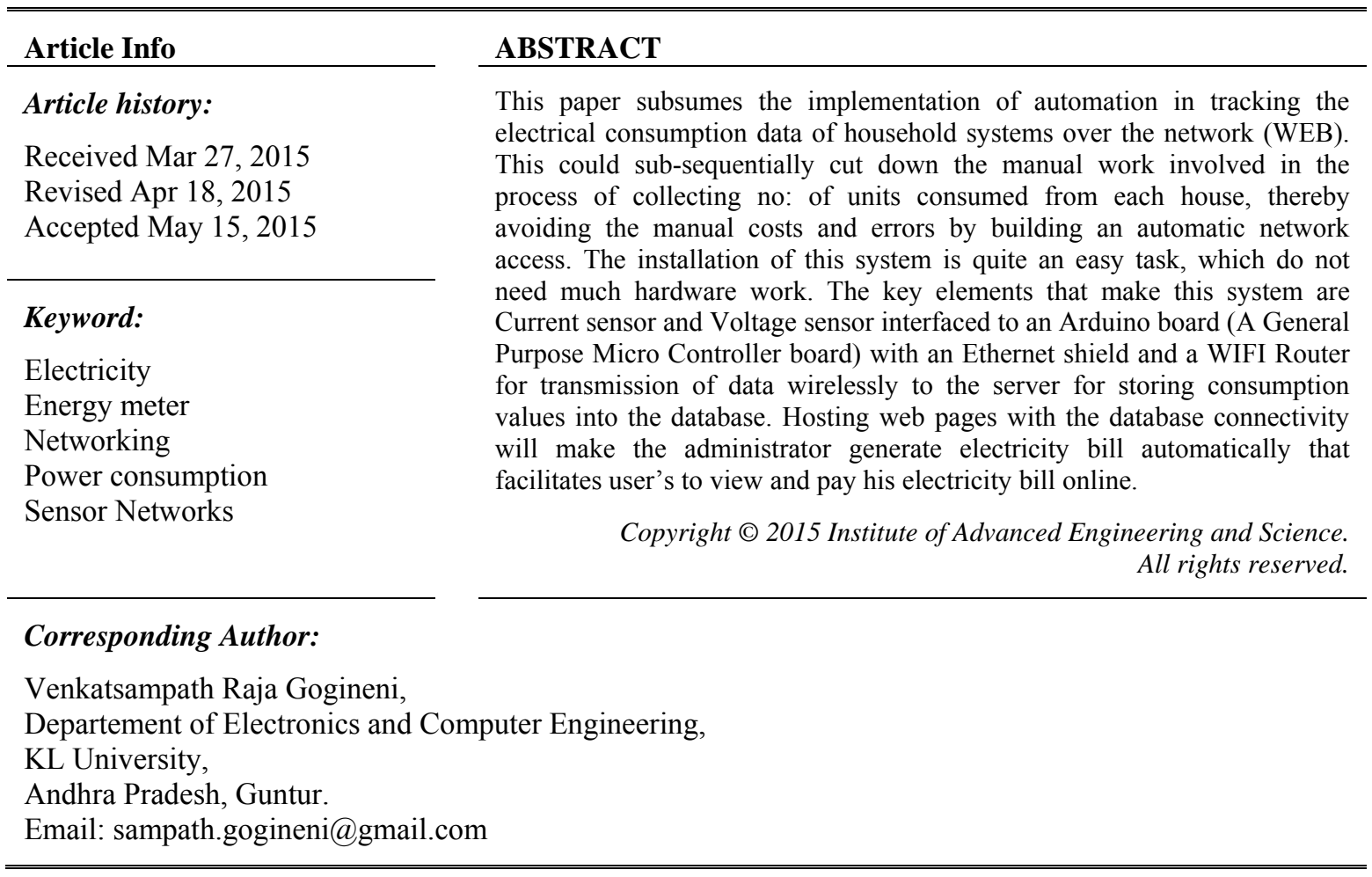

\section{INTRODUCTION}

India being the second most populous country in the world having more than 50 million households with electric connections, where every energy meter is read manually and the data is collected to the nearest electrical substation, the bills get generated and the billing system is done manually. The accuracy and the manual costs have become a major issue for electrical departments. With the advancements in the communication, networking and web technology there is a need to implement an automatic system which would cut down the manual costs, errors and the discrepancies in the manual system of paying the bill, the other severe problem that needs to overcome through the technology is maintaining the record of data unit by unit, advancements in DBMS could make this possible at a cheaper cost. There have been a lot of issues when an electric meter stops working at the middle of the month, according to the provisional system the meter gets replaced with the working one and arises an ambiguity of finding the units consumed for those 15 days as there would be no recordings.

There has been quite a reasonable amount of research work in building a networking system to electric meter like providing networking through zig-bee module [1], GSM module [2] or RFID [3] had become a costlier task with a greater maintenance. My system is nearly similar to this, where the data is sent to the database [4] but there could be the data loss or the packet loss if there would be a jammer or a disconnection, and the sensor node with the trans-receiver is a costlier technology to implement and the range is also quite limited. Prepaid energy meters [5] had also been proposed before, but this system is not well suited for household systems as the usage donot remain constant and the connections are permanent. Keeping in mind the economic view and the consequences of data loss, we have implemented the system with the main focus on the storage, security and the transmitting data wirelessly. 
This system uses sensors for measuring current and voltage. A general purpose micro-controller board (Arduino UNO) calculates the electrical parameters, Ethernet shield with an SD card and a WIFI Router is used for offline storage and transmission of data wirelessly to the server (database) which could be used to notify the consumption information to the user through the internet and the bill can be paid online.

\section{RESEARCH METHOD}

Figure 1 represents the block diagram of the system architecture, to the left represents the hardware that is to be installed in each house .Repeater or signal booster carry's the wireless signal to the nearest electrical substation. To the right represents the server with the database in the electrical substation.

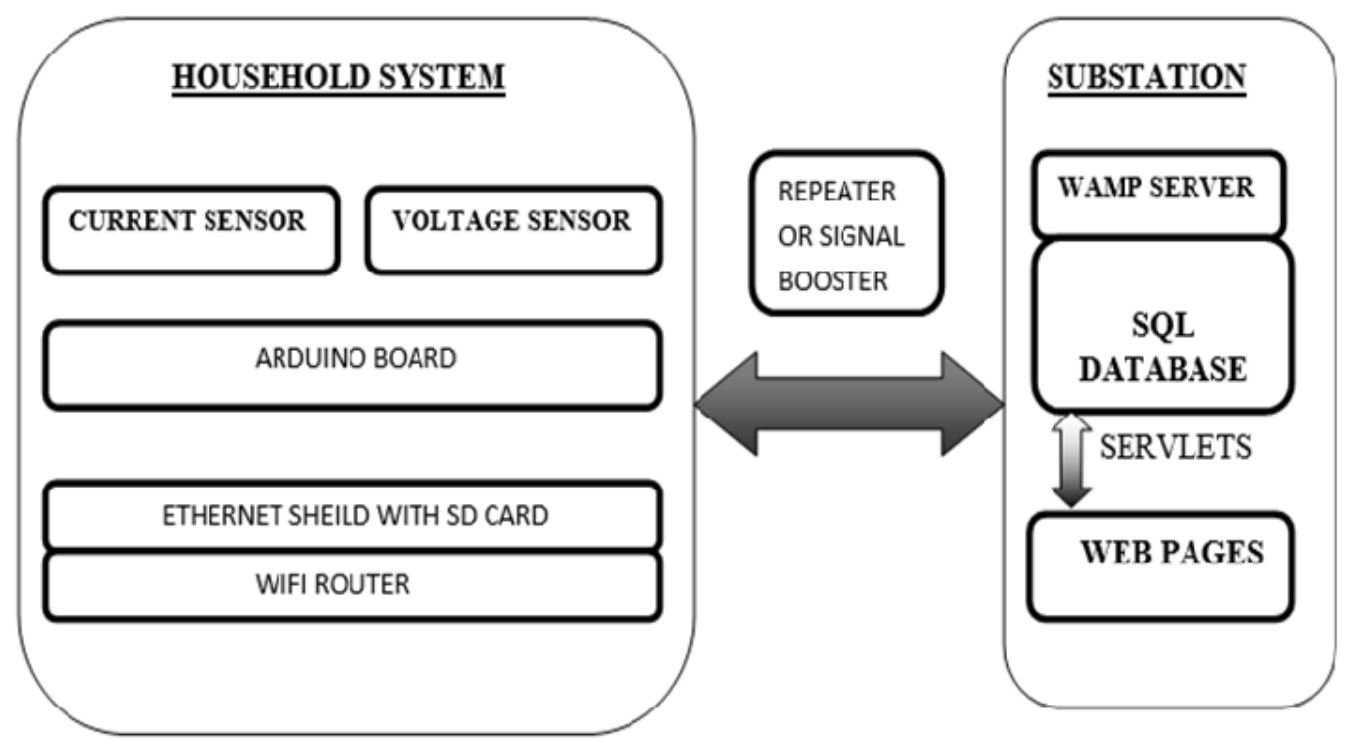

Figure 1. Block Diagram

\section{a. General Description}

The preliminary goal in generating an electricity bill is to calculate no: of units consumed. This depends on three parameters.

- Current

- Voltage

- Time

Power $=$ Voltage $*$ Current

Energy $=$ Power $*$ Time

With these basic formulae, we can calculate consumption in units.

- Current can be measured using CT Sensor

- Voltage can be measured using AC Adaptor

- Time can be calculated using clock circuit in the Arduino.

\section{b. Current Sensor}

Measuring the alternating current source is not an easy task, very few devices are available for measuring a great amount of load. Current Transformer (CT) sensors of split core are one such option where we can easily clip on to a phase wire and measure current proportionally that can be calibrated through software.

A current transformer consists of a primary coil, magnetic core and a secondary coil, alternating current flowing in the primary coil produces magnetic field which induces current proportional to the primary coil in the secondary coil. This current transformer is installed by clipping either the live or neutral wire coming into the electric meter with the CT, when incase both the wires are clipped then the currents get cancelled as they flow in opposite directions. For this application systems a typical CT transformer of model no SCT-00-13 is used which can measure a load of $100 \mathrm{~A}$ made proportional to $50 \mathrm{~mA}$ 


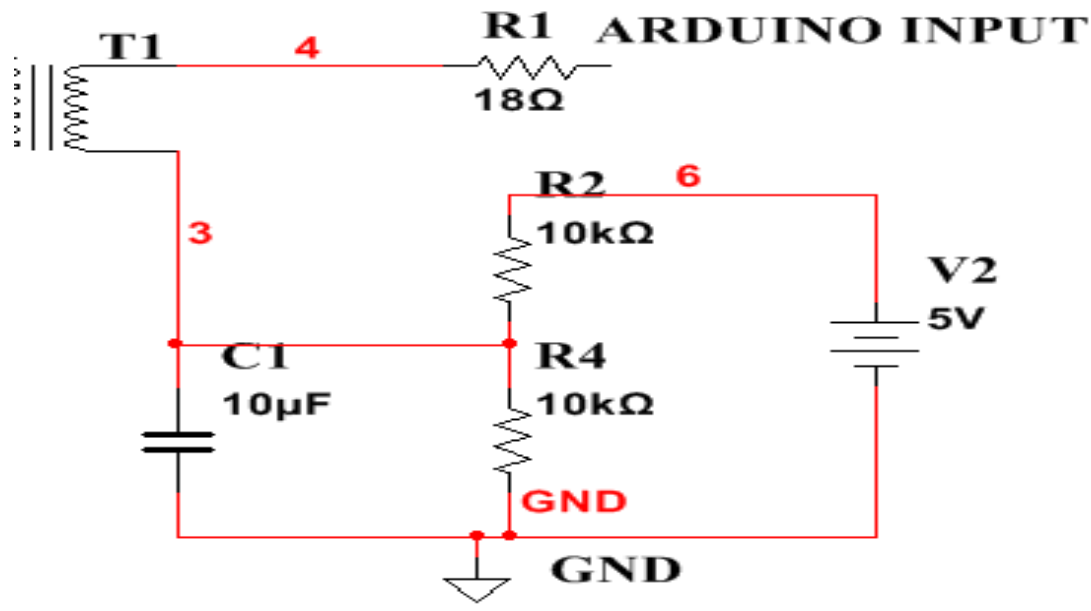

Figure 2. Circuit Diagram for Current Measurement

Figure 2 shows the circuitry connection to the output of the split core type transformer (CT). The output from the secondary transformer is made in-series with a resistor (R1) so that the obtained voltage output is stabilized with the DC bias could be given to the Arduino pin. Each pin in Arduino board could measure a value between 0 to $5 \mathrm{~V}$.

\section{Sensor specification Theory:}

$\mathrm{I}_{\text {secondary core }}=$ turns ratio $* \mathrm{I}_{\text {primary core }}$

Turns ratio $=$ no of turns in primary / no of turns in secondary

The no of turns in secondary is 2000 . So current measured through secondary is $2000^{\text {th }}$ part of primary.

b) Calculation regarding the maximum input to Arduino:

Consider the primary coil measuring of 100A rms current,

$$
\begin{gathered}
\mathrm{I}_{\text {peak to peak (primary) }}=\sqrt{2} * \mathrm{I}_{(\mathrm{Rms} \text { current })}=1.414 * 100 \mathrm{~A} \\
=141.4 \mathrm{~A}
\end{gathered}
$$

The secondary coil output,

$\mathrm{I}_{\text {secondary }}=\mathrm{I}_{\text {peak to peak (primary) }} /$ no of turns

$$
\begin{aligned}
& =141.4 / 2000 \\
& =0.0707 \mathrm{~A}
\end{aligned}
$$

Microcontroller input $=0.0707 \mathrm{~A} * 18 \Omega=1.272 \mathrm{~V}$

There by the max input is $1.272 \mathrm{~V}$.

c) Current Calibration:

Calibrated value $=141.4 / 1.272$

$$
=111.11
$$

These values are practically compared to the values from the clamp meter.

\section{c. Voltage Sensor}

Voltage can be sensed by using an AC adapter, in order to scale down the output voltage to less than $5 \mathrm{v}$ a voltage divider circuit is used and DC bias is added to stabilize the signal.

The adaptor voltage output (AC) implemented in the system was $9 \mathrm{~V}$ for $230 \mathrm{~V}$ input when it is loaded, in no load condition due to the transformer regulation it is $25 \%$ higher which also depends upon the adaptor design conditions. The voltage divider divides the circuit voltage further so that the actual input to Arduino will be less than 5V. 


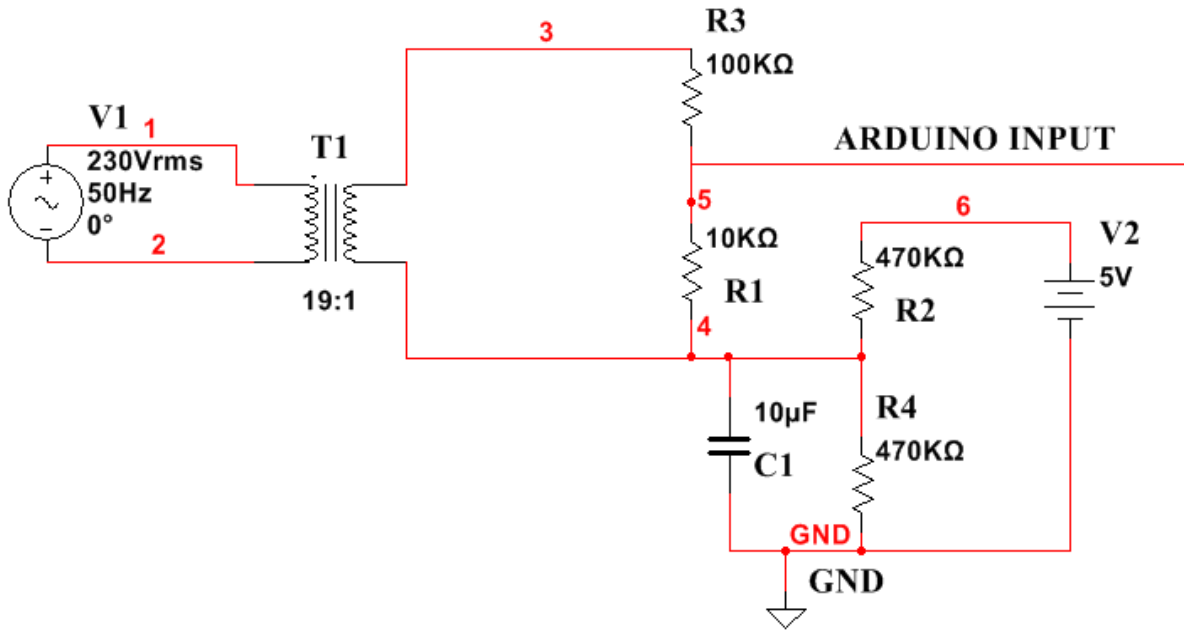

Figure 3. Circuit Diagram for Voltage Measurement

Figure 3. Represents the circuit diagram implemented in NI Multisim, with the voltage input 230V and $50 \mathrm{~Hz}$. The transformer T1 is the configuration of the transformer in the practical AC adaptor. R3 and R1 constitutes the voltage divider circuit, and the rest provide the DC bias to stabilize the Arduino Input.

$\mathrm{V}_{\text {Adapter output voltage }}=\mathrm{V}_{\text {mains voltage }} *$ transformer ratio $\mathrm{V}_{\text {Input voltage }}=(\mathrm{R} 1 /(\mathrm{R} 1+\mathrm{R} 3)) * \mathrm{~V}_{\text {Adaptor output voltage }}$

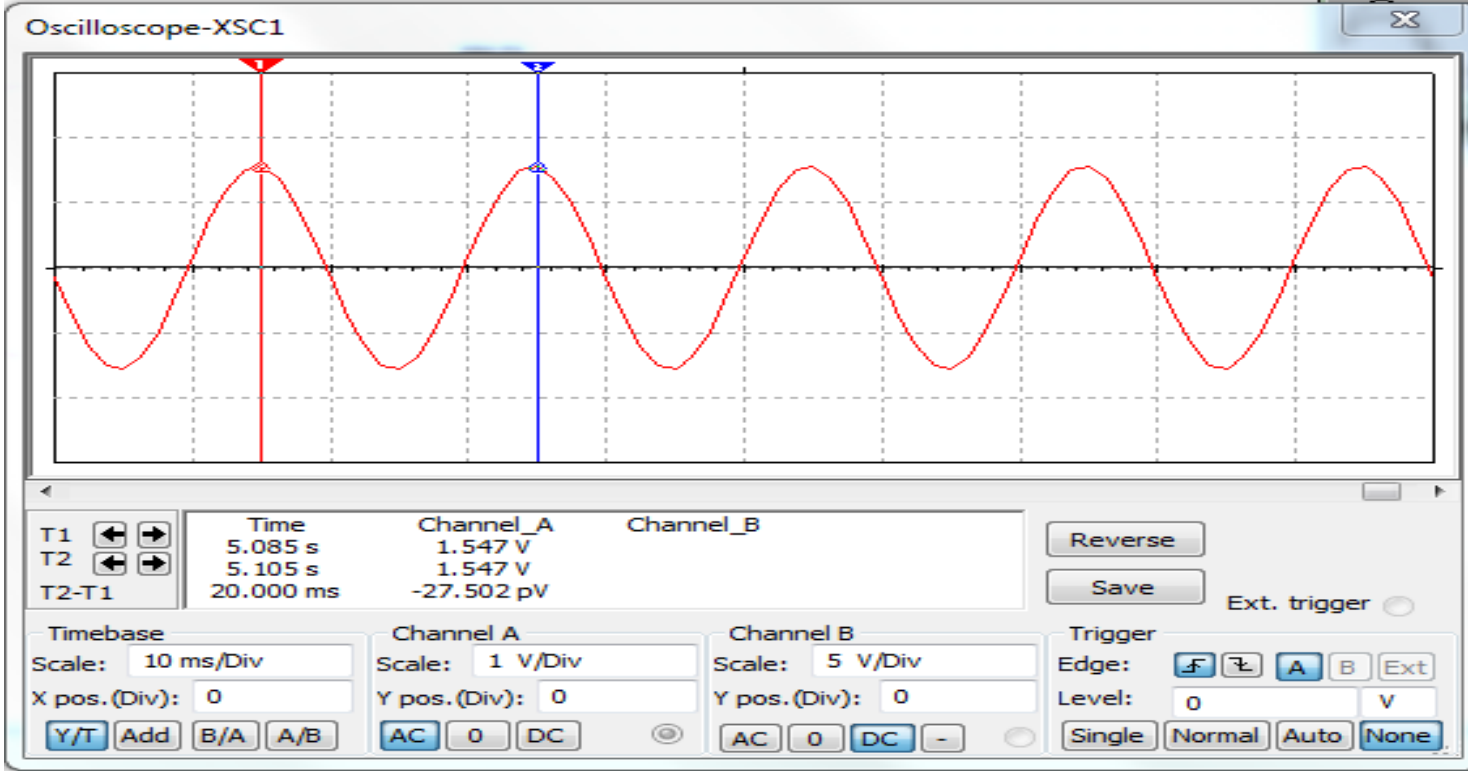

Figure 4. Output Waveform for 230V input

Figure 4 gives the stimulation output implemented in NI Multisim for input Voltage $230 \mathrm{~V}$ and $50 \mathrm{~Hz}$ frequency the peak voltage output corresponds to $1.547 \mathrm{~V}$.

\section{Calibration Value:}

Voltage calibration $=$ alternating mains voltage $/$ alternating input voltage

Due to the tolerances in manufacturing the components, the calibrated value is adjusted by the difference that is obtained while measuring the mains voltage with multi-meter. 


\section{d. Arduino Board}

Arduino is a general purpose micro-controller that can be programmed by using Arduino IDE software. It consists of a microcontroller with on-chip memory and pins for interfacing external devices.

Arduino is both an open source hardware and softwareThere are many variants in Arduino board. The one that used in this system is Arduino Uno. Microcontroller on the board is ATMEGA328.

- 14 digital input / output pins.

- Can be programmed using USB connection.

- $16 \mathrm{MHz}$ ceramic resonator.

- Operating voltage 5V

- Easy to attach libraries and program the board.

- $\quad$ Easy To interface External Devices.

- Serial Monitor in Arduino IDE can easily view sensor values on the screen.

\section{e. Etherner Sheild with Secure Digital (SD) Card}

An Arduino Ethernet shield contains its own physical address that can be used in connecting the server via a Wi-Fi router, which paves a path for the connection to be established with the server. By including a SQL library, the SQL queries can be executed by the Arduino board. Similarly including ethernet library could indulge a connection established with only the server's IP address which provides security in connection.

The Ethernet shield can be interfaced with the Arduino board and can be connected to the router through an RJ45 cable; it consists of an external SD card which could be useful in maintaining a backup copy of data that can be programmed.

In order to avoid the problem of disconnection with the server, for every few milliseconds it checks and reconnects to the server.

\section{f. Router}

The router provides a gateway to the server therefore when we consider a colony. Each house consists of a router and for every colony there exists a repeater or a signal booster which sends the signal to the nearest substation. When a local server with a database exists, the information gets updated into the database by the SQL query programmed with each Arduino device according to the User ID or Meter ID that was assigned to them and all the local servers get connected to a centralized sever and this server hosts a database.

\section{g. Server for Database Connectivity}

In order to connect the data incoming from the Ethernet shield in to the database there should be a server hosting the SQL database with the device IP. So the communication is established with the database through the port address that should be programmed in the Arduino using SQL library.

In the implementation, a Wamp server which is an open source does this purpose. It has an apache tom cat server hosting the MYSQL database at the port address 3306 with authentic privileges of username and password.

\section{h. Web Implementation}

The user with the authenticity could view his electricity usage information and pay his/her monthly bill, while he/she can even view the statistics of his/her usage as well. This can be established by hosting the web pages over the internet with a domain name and establishing a connection through JDBC between web pages and database by programming through servlets.

In the implementation we have three access privileges

1) Administrator

An administrator with authentic information of login id and password can register new users, modify user details, search for the user requests and assign user id along with his full details into the database. Admin will assign the user-id for the users whenever the user get registered in the website. After getting the user-id from the admin, users can login and check their electricity statistics in detail.

2) User

User could login with the authentic details of user-id and password. He/she can view his electricity usage details and could pay the bill online.

3) Guest

A new user could request a new connection to the administrator who can assign a user id after installing the hardware. 


\section{TESTING}

The Values of the current and the voltage for precision can be tested by establishing a USB connection between Arduino and Computer. These values can be viewed using a "Serial Monitor" which is present in the Arduino IDE.
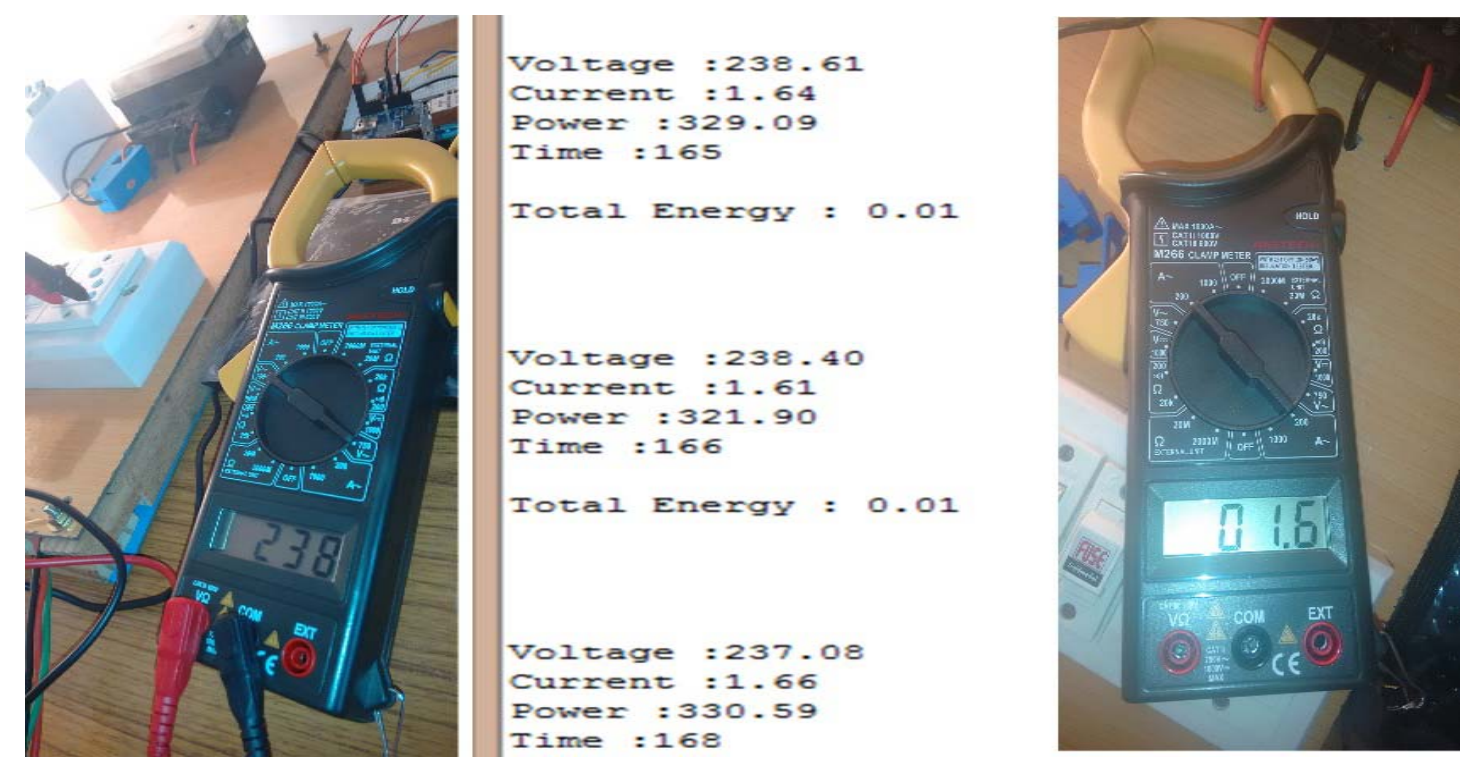

Figure 5. Testing of Voltage and Current values.

From the Figure 5, to the left represents the AC voltage measured, to the right represents the AC current with the clamp meter and the center represents the calibrated values obtained from the Arduino board through the Serial Monitor from the Arduino IDE.

\section{RESULTS AND IMPLEMENTATION}

\section{a. Prototype for System Architecture}

Figure 6 is the prototype of how the system has been implemented for a prototype purpose, where we have a Current sensor in blue color at phase wire, AC adaptor, Arduino board, with Ethernet shield and a router for transmitting the data wirelessly. Installing the sensor components is quite an easy task. This implementation had brought a great precision in the values obtained for several different long duration tests. 


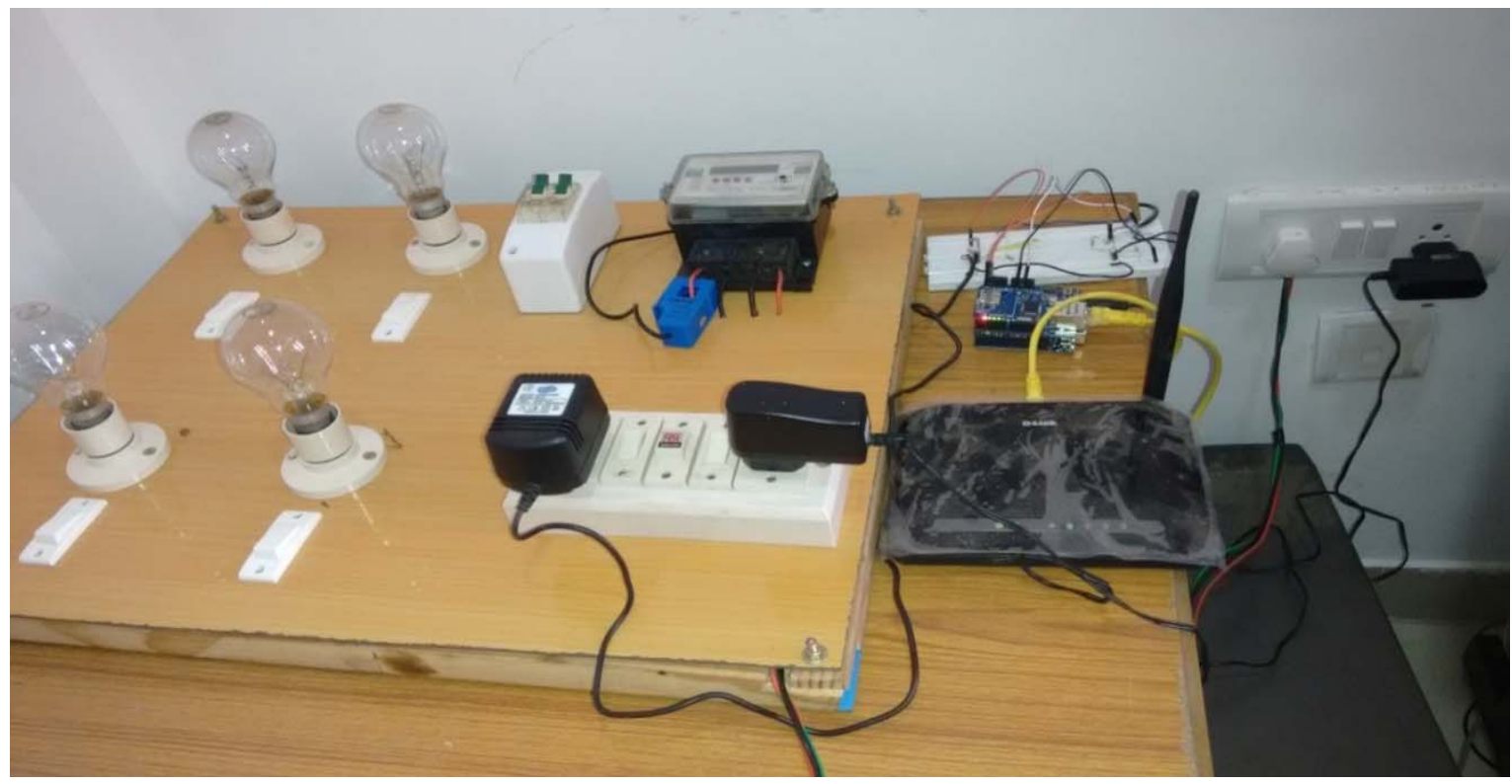

Figure 6. Implementation Prototype

\section{b. Database Values}

Values from each house (Arduino Board) continuously updates the column "UNITSCONSUMED" in the Figure 7 every second basing on the "USERID". For each and every update to the value in "UNITSCONSUMED" column the database connection is established so that there would be no loss in the connection to the server. Incase if any server failure occurs, the values that are stored in the SD card gets compared to the database values and gets updated when again a secure connection is established.

The "USERID" is the primary key for this table in the database.

\begin{tabular}{|c|c|c|c|c|}
\hline USERID NAME & EMAIL & PASSWORD & MOBILENO ADDRESS & UNITSCONSUMED \\
\hline 11005007 BHARATH & bharath@gmail.com & 123 & 9888888108 gandhinagar colony, ongole & 1.14 \\
\hline 11005106 KALYAN & kalyan@gmail.com & 123 & 8977798699 Lbnagar, vijayawada & 3.23 \\
\hline 11005245 ARAVIND & aravind@gmail.com & 123 & 9666833383 Moghalrajpuram, Vijayawada & 0.67 \\
\hline 11005248 SAMPATH & sampath.gogineni@gmail.com & 123 & 8686607090 vidyanagar, guntur & 1.64 \\
\hline
\end{tabular}

Figure 7. Database Values from wamp server

Maintaining the Record Of values Unit by Unit along with time could be useful in replacing the faulty systems, keeping the "USERID" as a foreign key and maintain the record of data could have a relation established with the table shown in the Figure 7. Figure 8 shows the different record of values unit by unit with the time in minutes. This record also shows the average voltage, average current, average power, time duration which could be useful for displaying a timely graphical usage charts. 


\begin{tabular}{|l|r|r|r|r|r|}
\hline USERID & CURRENT & VOLTAGE & POWER & TIME & ENERGY \\
\hline 11005007 & 1.63 & 242.07 & 394.57 & 143 & 1 \\
\hline 11005106 & 1.84 & 238.23 & 438.34 & 118 & 1 \\
\hline 11005106 & 1.92 & 238.54 & 457.99 & 112 & 2 \\
\hline 11005106 & 1.45 & 238.26 & 345.47 & 164 & 3 \\
\hline 11005248 & 2.34 & 241.36 & 564.78 & 103 & 1 \\
\hline
\end{tabular}

Figure 8. Record of values Unit By Unit for each USERID from Wamp server

\section{c. Web Implementation}

The Database is quite useful in developing a practical web application that represents the data in a meaningful form and gives the privilege access to different types of accesses. With the Web implementation the user can view his/her usage any time and can pay the bill online, similarly the administrator could fix the issues with the online complaint form rather than reporting manually to the electrical office.

Figure 9 shows the collage of Web implementation for the services of administrator page. Where an Administrator with authentic login credentials can:

- Check for New Connections if any

- Validate and Assign meter id after installing essential hardware.

- Modify the Details of the User.
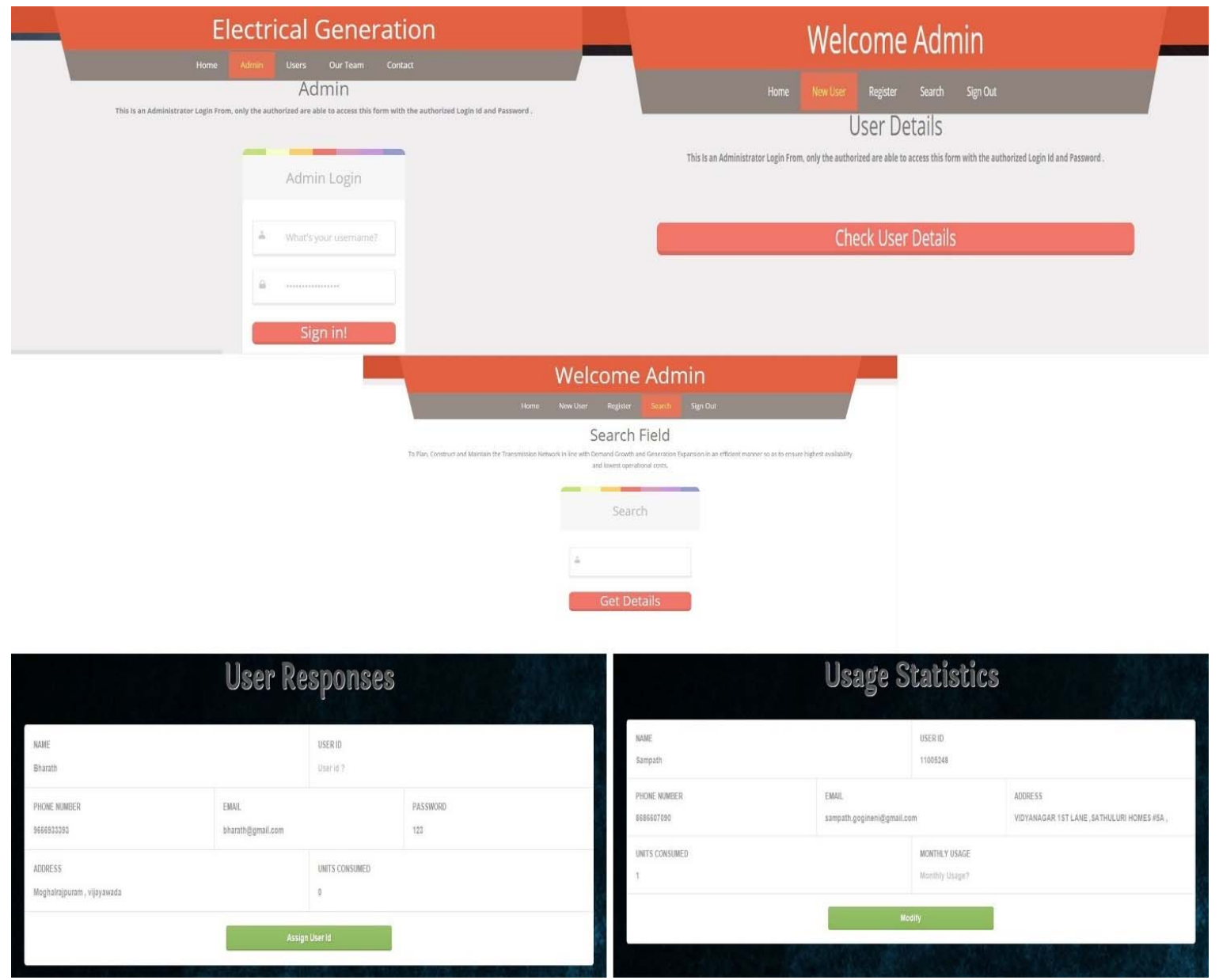

Figure 9. Collage of Web Implementation for Administrator 
Figure 10 shows the collage of Web implementation for the services of User page. Where a user with authentic login credentials can:

- Check his Usage Statistics

- $\quad$ Pay the Bill Online
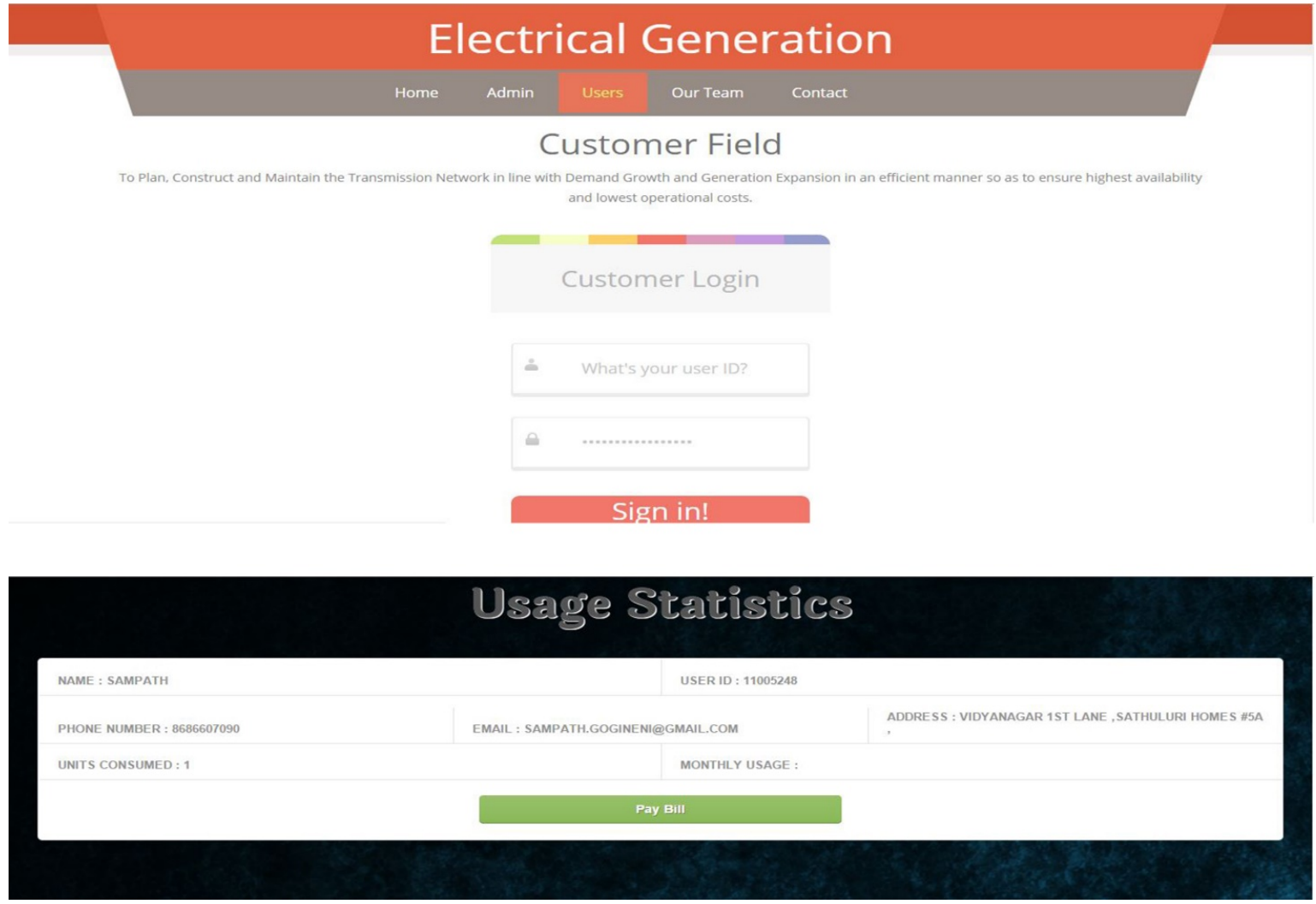

Figure 10. Collage of Web Implementation for User services

\section{CONCLUSION}

Keeping in view the Economic costs, security, precision, and in order to save the energy wastage utilized from reading the values to generating a bill. An Automated System will always have a less error rate when compared to a manual system. This system serves its best which would even facilitate the user with his up to date energy consumption activities. This system can be easily implemented to a house, a building more over to large industry as well.

\section{ACKNOWLEDGEMENTS}

This research paper is made possible through the help and support from everyone, including: parents, teachers, friends, and in essence, all sentient beings. I would like to thank K Sravya for her help and support. She kindly read my paper and offered invaluable detailed advices on grammar, organization, and the theme of the paper.

\section{REFERENCES}

[1] Chun-sen XU, Xiang-jian CHEN, Di LI, Xiu-hong Zhong, "Automatic Electric Meter Reading System Based on ZigBee", 2008, IEEE, pp: 1-4.

[2] Ashna.k, Sudhish N George, "GSM Based Automatic Energy Meter Reading System with Instant Billing”, 2013, IEEE, pp: 65-72.

[3] Wasana Boonsong and Widad Ismail, "Wireless Monitoring of Household Electrical Power Meter Using Embedded RFID with Wireless Sensor Network Platform", Hindawi Publishing Corporation International Journal of Distributed Sensor Networks Volume 2014, Article ID 876914, 10 pages. 
[4] Wibhada Naruephiphat, Chalermpol Charnsripinyo, Sadit Satienpaisarn, Ridnarong PromYa, "Applying Wireless Sensor Network for Power Consumption Monitoring", 2012, IEEE, pp: 1-4.

[5] Md. Kamal Hossain, Md. Mortuza Ali, Md. Rafiqul Islam Sheikh, "Microcontroller Based Single Phase Digital Prepaid Energy Meter for Improved Metering and Billing System”.

[6] Arduino Ethernet Sheild Usage is available at, http://www.arduino.cc/en/Main/ArduinoEthernetShield

[7] Arduino Uno Microcontroller board is available at http://www.arduino.cc/en/Main/arduinoBoardUno

\section{BIOGRAPHIES OF AUTHORS}

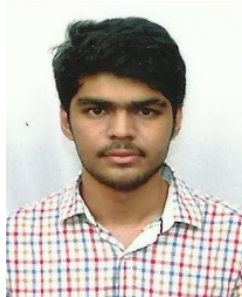

Venkat Sampath Raja Gogineni is studying B.Tech (Electronics and Computer Engineering) at KL University, Vijayawada. His areas of interest includes computer Networks, wireless Networks, Embedded Systems, DBMS, Web technologies. Previously he had done research paper in area of Networking Security titled as "An Enhanced CBC Algorithm for Data Security in the Cloud". He attended various workshops on e-commerce, programmable system on chip, and Robotics.

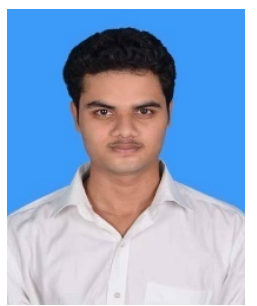

M. Kalyan, studying B. Tech final year in the dept. of ECM in K L University. His areas of interests are Computer networks and database management system. He has done projects on client/server system technology based on TCP/IP protocols and Database Management System (DBMS). He also attended the workshop on Network security and also done internship for two months on Computer Networks. He published a paper on Multimedia Database for attainment targets.

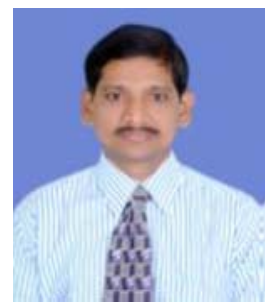

Raghava Rao, Professor in Electronics \& Computer Engg., working in the dept. of ECM. He is having 15 years of experience in teaching for UG and PG engineering students and 3 years of Software Development experience in Singapore. He received B.E (CSE) from MG state University, M.Tech (CSE) from RVP University, Udaipur and Ph.D (CSE) from Mahatma Gandhi University (Kasi Vidyapeeth), Varanasi, in the years 1995, 2005 and 2009 respectively. He published several papers in national \& international conferences and journals. He published 3 text books. Currently he is carrying a DST funded project in the area of Wireless sensor networks-sensor web enablement. His research interests are Wireless sensor networks, Embedded Sensor networks. He received a best paper award from DST Secretary and Best Teacher award from KL University He is also member of several technical organization 